\title{
Circuit
}

Musiques contemporaines

\section{Un pays à faire : vers un choix (projets du pays qui vient)}

\section{Gilles Tremblay}

Volume 5, numéro 1, 1994

Gilles Tremblay : réflexions

URI : https://id.erudit.org/iderudit/902091ar

DOI : https://doi.org/10.7202/902091ar

Aller au sommaire du numéro

Éditeur(s)

Les Presses de l'Université de Montréal

ISSN

1183-1693 (imprimé)

1488-9692 (numérique)

Découvrir la revue

Citer cet article

Tremblay, G. (1994). Un pays à faire : vers un choix (projets du pays qui vient). Circuit, 5(1), 57-59. https://doi.org/10.7202/902091ar d'utilisation que vous pouvez consulter en ligne.

https://apropos.erudit.org/fr/usagers/politique-dutilisation/ 


\section{Vers un choix (projets du pays qui vient)}

I Paru dans Possibles, vol. 4, no 2, hiver 1980.

C'est avec joie que j'accepte l'invitation de Possibles, d'autant plus qu'elle est signée par un poète. La parole du poète n'estelle pas celle qui nous incite au réel le plus profond ¿ Elle veille à l'authenticité du mot, à travers l'incessant clivage des choix. Or la réflexion et le témoignage auxquels vous nous conviez dans le contexte politique présent, se situent précisément dans cette perspective du choix. Les mots oui/non ne doivent pas être vidés de sens.

Ici, aujourd'hui, au seuil de toutes les hypothèses, en un rêve qui peut être réel, s'accepter tels que nous sommes, accueillir avec tendresse ce pays naissant, nôtre.

\section{Jeu litanique}

Oui au choix. Oui aux possibles. Oui au risque, oui à la confiance. Non à l'uniformisation. Non aux ivresses du pouvoir. Non à la tergiversation. Non à la confusion systématisée. Oui à l'accueil. Oui à l'hospitalité. Oui à l'ouverture à l'univers, à travers ce sentiment d'appartenance à une communauté.

- «... Et pas seulement l'appartenance à une communauté mais à l'univers, à la terre, à l'air, à l'eau, à tous les vivants. »

Jean Vanier, La communauté..., Paris-Montréal, 1979

Oui à la responsabilité, oui à la clarification. Oui à l'autocritique. Non à la complaisance. Non au dessèchement du repli sur soi. Non à la suffisance. Non à l'indigence des politiques culturelles. Oui à nos racines mais non au passéisme folklorisant. Non au dirigisme culturel. Non à la négation de soimême. Oui à la relation franche et amicale mais non au «bon entendisse " de façade. Non à la démission. Oui à l'humour. 
... Notre descendance aura peutêtre, à la suite des grandes migrations futures, les yeux bridés, quelquefois bleus, d'où s'esquisse une perspective merveilleuse de synthèse culturelle franco-chinoise, ne serait-ce que dans le domaine culinaire...

\section{Complémentarité des contraires}

Alternance universelle.

"Accords de tensions inverses, comme dans l'arc et la lyre ".

Héraclite d'Ephèse

Tensions inverses, source de dynamisme fécond qui s'oppose à la stagnation des grands courants actuels vers l'uniformisation, mortellement déshumanisants. La présente démarche politique participe à ce combat, elle en est un des signes. En l'accueillant nous dirons: oui à l'éveil.

\section{Rêve-vœux}

Qu'après avoir secoué la poussière de la Religion nous sachions, abandonnant toute fixation stérile, en discerner le cœur et la Source. - Le fleuve aux ondes de fécondité auprès duquel nous sommes nés nous y incite. - Nous redécouvrirons le sens ineffable de ce mot: re - lien entre les hommes et Dieu. Ouverts à l'Esprit incarné dont le travail en nous dépasse en merveille toute imagination, nous pourrons dire du plus profond des fibres de l'être, et en Vérité à la suite de Jésus-Christ, notre voix fondue à la sienne, cette parole vraiment universelle, délicatement formée de tous les ici: «Notre Père... ».

\section{Art, politique, choix}

Associer art et politique est dangereux car on pense le plus souvent à un art politisé, ce qui lui est fatal, entraînant sa décadence par démission, en un reniement de lui-même puisqu'il est par essence expression de liberté. II n'y a qu'à s'en référer au réalisme-socialiste pour s'en convaincre.

Par contre, renverser les influences en une politique s'inspirant de l'art pourrait se révéler étonnamment stimulant. En effet, l'art, la création manifestent un sens aigu de la liberté, du choix, en une responsabilité assumée dans toutes ses conséquences jusqu'en ses ramifications les plus fines par l'individu, même 
dans les œuvres collectives (cathédrales). Transporter cet esprit en politique pourrait donner une organisation sociale très décentralisée, favorisant l'initiative, l'échange et l'invention à tous les niveaux, y compris et surtout à ceux des petits groupes et des individus. "Small is beautiful», selon la théorie d'un célèbre économiste (Schumacher). Cela n'exclut pas la conscience de la solidarité et de sa grandeur, mais rejette par contre le rouleau compresseur de l'uniformité.

Tel est le sens le plus profond et le plus généreux que l'on peut discerner dans la démarche politique présente. Amorçant une évolution qui dépasse les buts immédiats, elle est éminemment actuelle en cette fin de siècle, - voie partagée, disons-le, sans aucune emphase - contemporaine et ancestrale à la fois, avec tous ceux qui proclament la dignité de David face à Goliath. Dans le contexte nord-américain, elle ne peut être qu'éclairante, riche en échanges vitaux et en amitié.

Le geste que nous allons poser prend dans cette optique sa pleine dimension, en un choix créateur.

... Au-delà de toutes les raisons, accueillir avec tendresse ce pays naissant, nôtre...

Tel est le sens le plus direct et le plus simple de notre oui. 